\title{
IDENTIFIKASI FAKTOR YANG MEMENGARUHI ANAK PUTUS SEKOLAH DI KABUPATEN BADUNG
}

\author{
Ni Komang Ayu Sri Cahyani ${ }^{1 \S}$, Ni Luh Putu Suciptawati ${ }^{2}$, I Komang Gde Sukarsa ${ }^{3}$
}

\author{
${ }^{1}$ Program studi Matematika, Fakultas MIPA-Universitas Udayana [Email: cahyaayu36@yahoo.co.id] \\ 2 Program studi Matematika, Fakultas MIPA-Universitas Udayana [Email: suciptawati@unud.ac.id] \\ 3 Program studi Matematika, Fakultas MIPA-Universitas Udayana [Email: sukarsakomang@yahoo.com] \\ ${ }^{\S}$ Corresponding Author
}

\begin{abstract}
School dropout is someone who has left school before she/he has finished her/his study. This research aims to identify the factors that affects school dropout in Badung Regency. The research method used is confirmatory factor analysis and obtained six factors that affects school dropout, namely the lack of interest and willingness of children to go to school, the view that school is considered unattractive by student, inability to take lessons, economic family, lack of parental attention, and children's play environment. The results of factor analysis which shows that the most dominant factor that affects school dropout in junior high school level is lack of parental attention, in senior high school the factors are lack of interest and willingness of children to go to school.
\end{abstract}

Keywords: School dropout, Factor analysis, Badung Regency

\section{PENDAHULUAN}

Analisis faktor merupakan suatu teknik interdependensi untuk menganalisis saling ketergantungan beberapa peubah dengan tujuan untuk menyederhanakan bentuk hubungan antarpeubah awal yang diteliti menjadi sejumlah faktor yang lebih sedikit dari peubah awal (Hair,et al., 2010). Pada dasarnya analisis faktor mendekatkan data pada suatu pengelompokan atau pembentukan suatu peubah baru berdasarkan adanya kekuatan hubungan antardimensi pembentuk faktor atau adanya konfirmatori sebagai peubah baru yang disebut dengan faktor. Hasil yang diharapkan adalah faktor-faktor yang nantinya terbentuk tidak saling berkorelasi lagi.

Menurut Hair, et al. (2010), analisis faktor dapat dibedakan menjadi dua jenis, yaitu analisis faktor eksploratori dan analisis faktor konfirmatori. Pada analisis faktor eksploratori tidak dilakukan hipotesis yang bersifat teoretis, sehingga kesimpulan pengelompokan pada faktor akan dibuat berdasarkan apa yang diperoleh dalam analisis. Sedangkan, analisis faktor konfirmatori mempunyai informasi yang bersifat teoretis tentang struktur yang mendasari data dan diharapkan menghasilkan faktor yang sesuai dengan hipotesis tersebut.

Analisis faktor sering digunakan sebagai alat analisis dalam penelitian sosial, yang umumnya berupa data kualitatif. Kabupaten Badung merupakan daerah dengan laju pertumbuhan ekonomi yang tinggi, namun masih banyak ditemui kasus anak putus sekolah. Menurut Kamus Besar Bahasa Indonesia, anak putus sekolah adalah anak yang belum sampai tamat sekolahnya sudah berhenti. Menurut BPS (2017), pada tahun ajaran 2015/2016 tercatat sebanyak 11 murid SD/MI, 11 murid SLTP/MTs, dan 106 murid SMU/MA yang mengalami putus sekolah di Kabupaten Badung. Jumlah anak yang mengalami putus sekolah pada jenjang pendidikan SMU/MA ini berada pada peringkat dua di Provinsi Bali setelah Kabupaten Buleleng sebanyak 230 anak.

Bedasarkan permasalahan di atas, dilakukan analisis untuk mengetahui faktorfaktor yang memengaruhi anak putus sekolah di Kabupaten Badung. Analisis dilakukan dengan metode analisis faktor yang dilakukan pada jenjang pendidikan SMP/sederajat dan SMA/sederajat.

Analisis faktor adalah salah satu bagian 
dari teknik analisis multivariat yang digunakan untuk menganalisis saling ketergantungan antarpeubah, dengan tujuan utama yaitu untuk mengidentifikasi struktur yang terletak antara peubah yang dianalisis. Analisis ini memberikan gambaran mengenai struktur dari hubungan atau korelasi antar sejumlah besar peubah dengan menentukan suatu kelompok peubah yang memiliki korelasi tinggi yang disebut faktor (Hair, et al., 2010).

Secara umum, apabila terdapat sebanyak $p$ peubah asal dan $m$ faktor, maka model analisis faktornya dapat dinyatakan sebagai (Johnson dan Wichern, 2007):

$$
\begin{gathered}
X_{1}-\mu_{1}=l_{11} F_{1}+l_{12} F_{2}+\cdots+l_{1 m} F_{m}+\varepsilon_{1} \\
X_{2}-\mu_{2}=l_{21} F_{1}+l_{22} F_{2}+\cdots+l_{2 m} F_{m}+\varepsilon_{2} \\
\vdots \\
X_{p}-\mu_{p}= \\
l_{p 1} F_{1}+l_{p 2} F_{2}+\cdots+l_{p m} F_{m}+\varepsilon_{p} \\
\text { atau dapat dituliskan dalam bentuk matriks }
\end{gathered}
$$

$$
\begin{aligned}
{\left[\begin{array}{c}
X_{1}-\mu_{1} \\
X_{2}-\mu_{2} \\
\vdots \\
X_{p}-\mu_{p}
\end{array}\right]=} & {\left[\begin{array}{cccc}
l_{11} & l_{12} & \ldots & l_{1 m} \\
l_{21} & l_{22} & \ldots & l_{2 m} \\
\vdots & \vdots & \ddots & \vdots \\
l_{p 1} & l_{p 2} & \ldots & l_{p m}
\end{array}\right]\left[\begin{array}{c}
F_{1} \\
F_{2} \\
\vdots \\
F_{m}
\end{array}\right] } \\
& +\left[\begin{array}{c}
\varepsilon_{1} \\
\varepsilon_{2} \\
\vdots \\
\varepsilon_{p}
\end{array}\right]
\end{aligned}
$$

atau

$$
(X-\mu)_{p \times 1}=L_{p \times m} F_{m \times 1}+\varepsilon_{p \times 1}
$$

dengan $X_{1}, X_{2}, \ldots, X_{p}$ menyatakan peubah asal (indikator dari $m$ faktor), $\mu_{1}, \mu_{2}, \ldots, \mu_{p}$ menyatakan rataan variabel ke- 1 sampai ke- $p$, $L_{11}, L_{12}, \ldots, L_{p m}$ menyatakan loading factor dari peubah ke- $p$ pada faktor ke- $m, F_{1}, F_{2}, \ldots, F_{m}$ menyatakan faktor ke- 1 sampai ke- $m$, dan $\varepsilon_{1}, \varepsilon_{2}, \ldots, \varepsilon_{p}$ menyatakan galat (error) untuk peubah ke-1 sampai ke- $p$. Diasumsikan bahwa:

(i) $E(F)=0_{m \times 1}, \operatorname{Cov}(F)=E\left(F F^{\prime}\right)=I$,

(ii) $E(\varepsilon)=0_{p \times 1}, \operatorname{Cov}(\varepsilon)=E\left(\varepsilon \varepsilon^{\prime}\right)=$ $\psi_{(p \times p)}$,

(iii) $\operatorname{Cov}(\varepsilon, F)=E\left(\varepsilon F^{\prime}\right)=0_{(p \times m)}$.

Model orthogonal pada analisis faktor berakibat pada struktur kovarians untuk variabel acak $X$, yaitu:

$$
\begin{gathered}
(X-\mu)(X-\mu)^{\prime}=(L F+\varepsilon)(L F+\varepsilon)^{\prime} \\
=(L F+\varepsilon)\left((L F)^{\prime}+\varepsilon^{\prime}\right) \\
=L F(L F)^{\prime}+\varepsilon(L F)^{\prime}+L F \varepsilon^{\prime}+\varepsilon \varepsilon^{\prime} .
\end{gathered}
$$

Berdasarkan asumsi (i), (ii), dan (iii), maka persamaan matriks kovariansnya menjadi:

$$
\begin{aligned}
\Sigma= & \operatorname{cov}(X)=E(X-\mu)(X-\mu)^{\prime} \\
= & E\left[L F(L F)^{\prime}+\varepsilon(L F)^{\prime}+L F \varepsilon^{\prime}+\varepsilon \varepsilon^{\prime}\right] \\
& =L . I . L^{\prime}+0 . L^{\prime}+L .0+\psi \\
& =L L^{\prime}+\psi .
\end{aligned}
$$

Persamaan (4) dapat ditulis sebagai:

$$
\begin{aligned}
\operatorname{Var}\left(X_{i}\right) & =l_{i 1}^{2}+\cdots+l_{i m}^{2}+\psi_{i} \\
\operatorname{Cov}\left(X_{i}, X_{k}\right) & =l_{i 1 l_{k 1}}+\cdots+l_{i m} l_{k m}
\end{aligned}
$$

Perhatikan bahwa:

$$
\begin{aligned}
(X-\mu) F^{\prime} & =(L F+\varepsilon) \mathrm{F}^{\prime} \\
& =L F F^{\prime}+\varepsilon F^{\prime} .
\end{aligned}
$$

Oleh karena itu, kovarians untuk variabel acak $X$ dan faktor umum $F$, yaitu:

$$
\begin{aligned}
\operatorname{Cov}(X, F) & =\mathrm{E}(\mathrm{X}-\mu) \mathrm{F}^{\prime} \\
& =E\left[L F F^{\prime}+\varepsilon F^{\prime}\right] \\
& =L . I+0 \\
& =L .
\end{aligned}
$$

Secara umum dapat dituliskan sebagai:

$$
\begin{gathered}
\operatorname{Cov}\left(X_{i} F_{j}\right)=l_{i j} \\
\text { dengan } i=1,2, \ldots, p \text { dan } j=1,2, \ldots, m
\end{gathered}
$$

Varians dari variabel ke- $i$ yang disumbangkan oleh $m$ common faktor disebut komunalitas ke- $i$. Nilai $\operatorname{Var}\left(X_{i}\right)=\sigma_{i i}$ merupakan nilai komunalitas yang ditambahkan dengan nilai varians spesifik atau uniknya. Dari persamaan (5) dan persamaan (6) diperoleh:

$$
\underbrace{\sigma_{i i}}_{\operatorname{Var}\left(X_{i}\right)}=\underbrace{l_{i 1}^{2}+l_{i 2}^{2}+\cdots+l_{i m}^{2}}_{\text {kumunalitas }}+\underbrace{\psi_{i}}_{\begin{array}{c}
\text { varians } \\
\text { spesifik }
\end{array}} .
$$

Komunalitas ke- $i$ dinotasikan dengan $h_{i}^{2}$, dengan menggunakan notasi di atas diperoleh persamaan:

$$
\begin{aligned}
& h_{i}^{2}=l_{i 1}^{2}+l_{i 2}^{2}+\cdots+l_{i m}^{2} \\
& \sigma_{i i}=h_{i}^{2}+\psi_{i}, \quad i=1,2, \ldots, p
\end{aligned}
$$

Nilai komunalitas ke- $i$ merupakan jumlah kuadrat dari loading factor variabel ke-i pada $m$ factor.

\section{METODE PENELITIAN}

Data yang digunakan dalam penelitian ini adalah data primer yang diperoleh dengan metode survei melalui penyebaran kuesioner kepada anak yang mengalami putus sekolah. Peubah yang digunakan dalam penelitian ini merupakan peubah-peubah yang diindikasikan menjadi penyebab anak putus sekolah menurut 
Suyanto (2013), yaitu anak putus sekolah karena rendahnya minat dan kemauan anak untuk bersekolah, sekolah dianggap tidak menarik, ketidakmampuan mengikuti pelajaran, ekonomi keluarga, kurangnya perhatian orang tua, dan lingkungan bermain. Skala pengukuran peubah dalam penelitian ini adalah skala rasio dari 0 sampai dengan 100, dengan 0 menyatakan sangat tidak setuju dan 100 menyatakan sangat setuju.

Sampel dalam penelitian ini yaitu 150 anak yang mengalami putus sekolah pada jenjang pendidikan SMP/sederajat dan 150 anak yang mengalami putus sekolah pada jenjang pendidikan SMA/sederajat dengan teknik pengambilan sampel yang digunakan yaitu teknik purposive sampling dan quota sampling.

Tahapan yang dilakukan dalam penelitian ini adalah perancangan kuesioner penelitian, penyebaran kuesioner kepada responden, pemeriksaan kelengkapan jawaban kuesioner, pengujian validitas dan reliabilitas item kuesioner, mendeskripsikan karakteristik dari responden, melakukan analisis data dengan analisis faktor. Adapun langkah-langkah dalam analisis faktor, yaitu menguji kelayakan data, melakukan ekstraksi faktor dengan analisis komponen utama, menentukan banyaknya faktor, interpretasi faktor yang diawali dengan pengelompokkan item yang mempunyai faktor pembobot tinggi ke dalam faktor, kemudian dilakukan penamaan untuk masing-masing faktor.

Setelah diperoleh hasil dari analisis faktor, maka diidentifikasi lebih lanjut apakah terdapat perbedaan antara faktor yang paling dominan dalam memengaruhi anak putus sekolah pada jenjang pendidikan SMP/sederajat dan anak yang putus sekolah pada jenjang pendidikan SMA/sederajat.

\section{HASIL DAN PEMBAHASAN}

Analisis dalam penelitian ini dilakukan pada masing-masing jenjang pendidikan secara terpisah.

\section{Uji Validitas dan Reliabilitas Kuesioner}

Uji Validitas dan reliabilitas kuesioner menunjukkan bahwa terdapat beberapa item kuesioner yang memiliki nilai item total korelasi yang kurang dari 0.3 , sehingga tidak digunakan dalam analisis lebih lanjut. Setelah item kuesioner yang tidak valid dikeluarkan dan setiap dimensi memiliki nilai Alpha
Cronbach lebih besar dari 0.6, terdapat 22 butir kuesioner yang dapat digunakan dalam menganalisis faktor yang memengaruhi anak putus sekolah pada jenjang pendidikan SMP/sederajat dan 24 item kuesioner pada jenjang pendidikan SMA/sederajat.

\section{Karakteristik Responden}

Responden anak putus sekolah pada jenjang pendidikan SMP/sederajat dan SMA/sederajat di Kabupaten Badung didominasi oleh laki-laki. Hal ini berbeda dengan data jumlah anak putus sekolah di Provinsi Bali yang didominasi oleh perempuan. Menurut Sentana (2014), rendahnya akses pendidikan bagi perempuan disebabkan oleh adanya budaya patriarki, yaitu pandangan untuk mengutamakan laki-laki dalam memperoleh pendidikan. Hal ini disebabkan karena masih adanya anggapan apabila perempuan berpendidikan tinggi maka yang menikmati adalah keluarga suaminya, namun apabila laki-laki yang berpendidikan tinggi maka ia dapat meningkatkan derajat keluarganya. Hal seperti ini memang masih terlihat di Provinsi Bali, namun di Kabupaten Badung dan Kota Denpasar kebudayaan yang menempatkan laki-laki lebih penting dari perempuan dalam hal memperoleh pendidikan sudah semakin terkikis. Oleh karena itu, kesempatan yang sama untuk memperoleh pendidikan diberikan kepada anak laki-laki dan perempuan.

\section{Uji Kelayakan Data}

Uji kelayakan data yang digunakan dalam analisis faktor dapat dilihat dengan melakukan uji Kaiser-Mayer-Olkin (KMO), Bartlett's Test of Sphericity, dan measure of sampling adequancy (MSA).

Tabel 1. Nilai KMO dan p-value Bartlett's Test Data SMP

\begin{tabular}{|l|r|}
\hline \multicolumn{2}{|c|}{ Nilai KMO dan Uji Bartlett } \\
\hline $\begin{array}{l}\text { Kaiser-Meyer-Olkin Measure of } \\
\text { Sampling Adequacy }\end{array}$ & 0,646 \\
\hline Approx, Chi-Square & 3552,332 \\
\hline Bartlett's Test of Sphericity df & 231 \\
\hline Sig. & 0,000 \\
\hline
\end{tabular}


Tabel 2. Nilai Measure of Sampling Adequacy (MSA) Data SMP

\begin{tabular}{|c|c|c|c|}
\hline Dimensi & Indikator & $\begin{array}{l}\text { Nilai } \\
\text { MSA }\end{array}$ & Keterangan \\
\hline \multirow{5}{*}{$\mathrm{X} 1$} & $\mathrm{X} 11$ & 0,651 & Memadai \\
\hline & $\mathrm{X} 12$ & 0,728 & Memadai \\
\hline & $\mathrm{X} 13$ & 0,624 & Memadai \\
\hline & $\mathrm{X} 14$ & 0,812 & Memadai \\
\hline & $\mathrm{X} 15$ & 0,922 & Memadai \\
\hline \multirow{3}{*}{$\mathrm{X} 2$} & $\mathrm{X} 21$ & 0,820 & Memadai \\
\hline & $\mathrm{X} 24$ & 0,731 & Memadai \\
\hline & $\mathrm{X} 25$ & 0,758 & Memadai \\
\hline \multirow{3}{*}{$\mathrm{X} 3$} & $\mathrm{X} 31$ & 0,664 & Memadai \\
\hline & $\mathrm{X} 32$ & 0,692 & Memadai \\
\hline & X33 & 0,627 & Memadai \\
\hline \multirow{4}{*}{$\mathrm{X} 4$} & $\mathrm{X} 41$ & 0,500 & Memadai \\
\hline & $\mathrm{X} 42$ & 0,558 & Memadai \\
\hline & $\mathrm{X} 43$ & 0,506 & Memadai \\
\hline & $\mathrm{X} 44$ & 0,512 & Memadai \\
\hline \multirow{4}{*}{$\mathrm{X} 5$} & X51 & 0,664 & Memadai \\
\hline & $\mathrm{X} 52$ & 0,751 & Memadai \\
\hline & $\mathrm{X} 53$ & 0,584 & Memadai \\
\hline & X54 & 0,662 & Memadai \\
\hline \multirow{3}{*}{ X6 } & $\mathrm{X} 62$ & 0,604 & Memadai \\
\hline & X63 & 0,644 & Memadai \\
\hline & X64 & 0,723 & Memadai \\
\hline
\end{tabular}

Sumber: Data primer yang diolah (2019)

Tabel 1 dan 2 Menunjukkan bahwa nilai Kaiser-Mayer-Olkin (KMO) sebesar 0,646> 0,6; $p$-value pada uji Bartlett's sebesar $0<\alpha$ $(0,05)$; dan nilai MSA semua indikator lebih besar dari 0,5. Oleh karena uji kelayakan data telah dipenuhi maka analisis faktor layak untuk dilakukan.

Tabel 3. Nilai KMO dan p-value Bartlett's Test Data SMA

\begin{tabular}{|l|r|}
\hline \multicolumn{2}{|c|}{ Nilai KMO dan Uji Bartlett } \\
\hline $\begin{array}{l}\text { Kaiser-Meyer-Olkin Measure of } \\
\text { Sampling Adequacy }\end{array}$ & 0,684 \\
\hline Approx, Chi-Square & 1541,553 \\
\hline Bartlett's Test of Sphericity df & 276 \\
\hline Sig. & 0,000 \\
\hline
\end{tabular}

Sumber: Data primer yang diolah (2019)
Tabel 4. Nilai measure of sampling adequacy (MSA) Data SMA

\begin{tabular}{|c|c|c|c|}
\hline Dimensi & Indikator & $\begin{array}{l}\text { Nilai } \\
\text { MSA }\end{array}$ & Keterangan \\
\hline \multirow{5}{*}{$\mathrm{X} 1$} & X11 & 0,811 & Memadai \\
\hline & $\mathrm{X} 12$ & 0,791 & Memadai \\
\hline & $\mathrm{X} 13$ & 0,729 & Memadai \\
\hline & X14 & 0,761 & Memadai \\
\hline & $\mathrm{X} 15$ & 0,811 & Memadai \\
\hline \multirow{3}{*}{$\mathrm{X} 2$} & $\mathrm{X} 21$ & 0,548 & Memadai \\
\hline & $\mathrm{X} 24$ & 0,624 & Memadai \\
\hline & $\mathrm{X} 25$ & 0,693 & Memadai \\
\hline \multirow{5}{*}{$\mathrm{X} 3$} & X31 & 0,713 & Memadai \\
\hline & X32 & 0,703 & Memadai \\
\hline & X33 & 0,610 & Memadai \\
\hline & X34 & 0,633 & Memadai \\
\hline & X35 & 0,705 & Memadai \\
\hline \multirow{4}{*}{$\mathrm{X} 4$} & X41 & 0,619 & Memadai \\
\hline & $\mathrm{X} 42$ & 0,731 & Memadai \\
\hline & $\mathrm{X} 43$ & 0,660 & Memadai \\
\hline & $\mathrm{X} 44$ & 0,655 & Memadai \\
\hline \multirow{4}{*}{ X5 } & X51 & 0,634 & Memadai \\
\hline & $\mathrm{X} 52$ & 0,641 & Memadai \\
\hline & X53 & 0,630 & Memadai \\
\hline & $\mathrm{X} 54$ & 0,638 & Memadai \\
\hline \multirow{3}{*}{ X6 } & X62 & 0,576 & Memadai \\
\hline & X63 & 0,595 & Memadai \\
\hline & X64 & 0,626 & Memadai \\
\hline
\end{tabular}

Sumber: Data primer yang diolah (2019)

Tabel 3 dan 4 Menunjukkan bahwa nilai Kaiser-Mayer-Olkin (KMO) sebesar 0,684 > 0,6; $p$-value pada uji Bartlett's sebesar $0<\alpha$ $(0,05)$; dan nilai MSA semua indikator yang lebih besar dari 0,5. Oleh karena uji kelayakan data telah dipenuhi maka analisis faktor layak untuk dilakukan.

\section{Jumlah Faktor}

Jumlah faktor pada penelitian ini didasarkan pada teori yang sudah ada. Menurut Suyanto (2013) terdapat enam faktor yang memengaruhi anak putus sekolah. Oleh karena itu, faktor yang diekstrak dalam analisis ini sebanyak enam faktor. Faktor yang terbentuk berdasarkan data anak putus sekolah dapat dilihat pada Tabel 5 berikut. 
Tabel 5. Jumlah Faktor Data SMP

\begin{tabular}{|c|c|c|c|c|c|c|}
\hline \multicolumn{7}{|c|}{$\begin{array}{c}\text { Total Variance } \\
\text { Explained } \\
\end{array}$} \\
\hline \multirow[t]{2}{*}{ Component } & \multicolumn{3}{|c|}{ Initial Eigenvalues } & \multicolumn{3}{|c|}{$\begin{array}{l}\text { Extraction Sums of Squared } \\
\text { Loadings } \\
\end{array}$} \\
\hline & Total & $\begin{array}{c}\% \text { of } \\
\text { Variance }\end{array}$ & $\begin{array}{c}\text { Cumulative } \\
\%\end{array}$ & Total & $\begin{array}{c}\% \text { of } \\
\text { Variance }\end{array}$ & $\begin{array}{c}\text { Cumulative } \\
\%\end{array}$ \\
\hline 1 & 5,613 & 25,515 & 25,515 & 5,613 & 25,515 & 25,515 \\
\hline 2 & 3,760 & 17,090 & 42,605 & 3,760 & 17,090 & 42,605 \\
\hline 3 & 3,120 & 14,180 & 56,784 & 3,120 & 14,180 & 56,784 \\
\hline 4 & 2,714 & 12,336 & 69,121 & 2,714 & 12,336 & 69,121 \\
\hline 5 & 1,530 & 6,955 & 76,076 & 1,530 & 6,955 & 76,076 \\
\hline 6 & 1,003 & 4,558 & 80,633 & 1,003 & 4,558 & 80,633 \\
\hline 7 & 0,799 & 3,630 & 84,264 & & & \\
\hline 8 & 0,639 & 2,903 & 87,167 & & & \\
\hline 9 & 0,472 & 2,147 & 89,314 & & & \\
\hline 10 & 0,418 & 1,901 & 91,215 & & & \\
\hline 11 & 0,396 & 1,801 & 93,016 & & & \\
\hline 12 & 0,312 & 1,416 & 94,433 & & & \\
\hline 13 & 0,286 & 1,301 & 95,734 & & & \\
\hline 14 & 0,270 & 1,227 & 96,962 & & & \\
\hline 15 & 0,241 & 1,098 & 98,059 & & & \\
\hline 16 & 0,176 & 0,799 & 98,858 & & & \\
\hline 17 & 0,088 & 0,402 & 99,260 & & & \\
\hline 18 & 0,057 & 0,260 & 99,520 & & & \\
\hline 19 & 0,049 & 0,222 & 99,742 & & & \\
\hline 20 & 0,033 & 0,150 & 99,892 & & & \\
\hline 21 & 0,016 & 0,074 & 99,966 & & & \\
\hline 22 & 0,008 & 0,034 & 100,000 & & & \\
\hline
\end{tabular}

Sumber: Data primer yang diolah (2019)

Tabel 5 menunjukkan bahwa terdapat dua puluh dua komponen yang kemudian diekstrak menjadi enam faktor. Keenam faktor tersebut mampu menjelaskan keragaman sebesar 80,633\%. Persentase keragaman yang mampu dijelaskan dari masing-masing faktor yang terbentuk, yaitu sebesar 5,613/22 (25,515\%); $3,760 / 33 \quad(17,090 \%) ; \quad 3,120 / 22 \quad(14,180 \%)$; $2,714 / 22 \quad(12,336 \%) ; 1,530 / 22 \quad(6,966 \%)$; dan $1,003 / 22(4,558 \%)$.

Faktor yang terbentuk berdasarkan data anak yang mengalami putus sekolah pada jenjang pendidikan SMA dapat dilihat pada Tabel 6. Tabel 6 Menunjukkan bahwa terdapat 24 komponen yang kemudian diekstrak menjadi enam faktor. Keenam faktor tersebut mampu menjelaskan keragaman sebesar 64,359\%. Persentase keragaman yang mampu dijelakan dari masing-masing dimensi, yaitu sebesar $4,380 / 24 \quad(18,249 \%) ; \quad 3,155 / 24 \quad(13,147 \%)$; $2,481 / 24(10,336 \%) ; 2,159 / 24(8,994) ; 1,806 / 24$ $(7,525 \%)$; dan $1,466 / 24(6,107 \%)$. 
Tabel 6. Jumlah Faktor Data SMA

\begin{tabular}{|c|c|c|c|c|c|c|}
\hline \multirow[t]{2}{*}{ Component } & \multicolumn{3}{|c|}{ Initial Eigenvalues } & \multicolumn{3}{|c|}{$\begin{array}{l}\text { Extraction Sums of Squared } \\
\text { Loadings }\end{array}$} \\
\hline & Total & $\begin{array}{c}\% \text { of } \\
\text { Variance }\end{array}$ & $\begin{array}{c}\text { Cumulative } \\
\%\end{array}$ & Total & $\begin{array}{c}\% \text { of } \\
\text { Variance }\end{array}$ & $\begin{array}{c}\text { Cumulative } \\
\%\end{array}$ \\
\hline 1 & 4,380 & 18,249 & 18,249 & 4,380 & 18,249 & 18,249 \\
\hline 2 & 3,155 & 13,147 & 31,397 & 3,155 & 13,147 & 31,397 \\
\hline 3 & 2,481 & 10,336 & 41,733 & 2,481 & 10,336 & 41,733 \\
\hline 4 & 2,159 & 8,994 & 50,727 & 2,159 & 8,994 & 50,727 \\
\hline 5 & 1,806 & 7,525 & 58,252 & 1,806 & 7,525 & 58,252 \\
\hline 6 & 1,466 & 6,107 & 64,359 & 1,466 & 6,107 & 64,359 \\
\hline 7 & 1,054 & 4,393 & 68,752 & & & \\
\hline 8 & 0,892 & 3,716 & 72,468 & & & \\
\hline 9 & 0,767 & 3,194 & 75,663 & & & \\
\hline 10 & 0,710 & 2,957 & 78,620 & & & \\
\hline 11 & 0,658 & 2,740 & 81,360 & & & \\
\hline 12 & 0,628 & 2,615 & 83,975 & & & \\
\hline 13 & 0,578 & 2,408 & 86,383 & & & \\
\hline 14 & 0,508 & 2,115 & 88,498 & & & \\
\hline 15 & 0,455 & 1,896 & 90,394 & & & \\
\hline 16 & 0,382 & 1,592 & 91,986 & & & \\
\hline 17 & 0,342 & 1,426 & 93,412 & & & \\
\hline 18 & 0,309 & 1,289 & 94,702 & & & \\
\hline 19 & 0,299 & 1,246 & 95,948 & & & \\
\hline 20 & 0,264 & 1,101 & 97,049 & & & \\
\hline 21 & 0,205 & 0,853 & 97,902 & & & \\
\hline 22 & 0,189 & 0,786 & 98,688 & & & \\
\hline 23 & 0,173 & 0,722 & 99,410 & & & \\
\hline 24 & 0,141 & 0,590 & 100,000 & & & \\
\hline
\end{tabular}

Sumber: Data primer yang diolah (2019)

\section{Interpretasi Faktor}

Interpretasi faktor diawali dengan melihat nilai faktor pembobot sesuai dengan jumlah sampel yang digunakan. Oleh karena jumlah sampel yang digunakan sebanyak 150, maka pemotongan nilai pembobot yang digunakan adalah 0,45 . Berdasarkan faktor pembobot yang ditentukan tersebut kemudian dilakukan pemeriksaan terhadap masing-masing indikator yang memiliki faktor pembobot minimal 0,45. Hasil dari analisis faktor yang dilakukan pada data anak yang mengalami putus sekolah pada jenjang pendidikan SMP dan SMA dapat dilihat pada Tabel 7 dan Tabel 8 berikut. 
Tabel 7. Hasil Analisis Faktor Data SMP

\begin{tabular}{|c|c|c|c|c|c|}
\hline Faktor & Nama Faktor & Indikator & $\begin{array}{l}\text { Nilai Akar } \\
\text { Ciri }\end{array}$ & $\begin{array}{c}\text { Persentase } \\
\text { Ragam }\end{array}$ & Nilai Pembobot \\
\hline \multirow{4}{*}{1} & \multirow{4}{*}{ Perhatian orang tua } & X51 & \multirow{4}{*}{5,613} & \multirow{4}{*}{$25,515 \%$} & 0,900 \\
\hline & & $\mathrm{X} 52$ & & & 0,875 \\
\hline & & $\mathrm{X} 53$ & & & 0,862 \\
\hline & & $\mathrm{X} 54$ & & & 0,831 \\
\hline \multirow{4}{*}{2} & \multirow{4}{*}{$\begin{array}{l}\text { Rendahnya kemauan } \\
\text { dan kesadaran anak } \\
\text { untuk bersekolah }\end{array}$} & $\mathrm{X} 11$ & \multirow{4}{*}{3,760} & \multirow{4}{*}{$17,090 \%$} & 0,770 \\
\hline & & $\mathrm{X} 13$ & & & 0,580 \\
\hline & & X14 & & & 0,668 \\
\hline & & $\mathrm{X} 15$ & & & 0,693 \\
\hline \multirow{4}{*}{3} & \multirow{4}{*}{ Ekonomi keluarga } & X41 & \multirow{4}{*}{3,120} & \multirow{4}{*}{$14,180 \%$} & 0,876 \\
\hline & & $\mathrm{X} 42$ & & & 0,896 \\
\hline & & $\mathrm{X} 43$ & & & 0,838 \\
\hline & & $\mathrm{X} 44$ & & & 0,331 \\
\hline \multirow{4}{*}{4} & \multirow{4}{*}{$\begin{array}{l}\text { Kurangnya } \\
\text { kemampuan dan } \\
\text { minat }\end{array}$} & $\mathrm{X} 12$ & \multirow{4}{*}{2,714} & \multirow{4}{*}{$12,336 \%$} & 0,625 \\
\hline & & X31 & & & 0,893 \\
\hline & & X32 & & & 0,773 \\
\hline & & X33 & & & 0,873 \\
\hline \multirow{3}{*}{5} & \multirow{3}{*}{ Buruknya hubungan } & $\mathrm{X} 21$ & \multirow{3}{*}{1,530} & \multirow{3}{*}{$6,955 \%$} & 0,724 \\
\hline & & $\mathrm{X} 24$ & & & 0,810 \\
\hline & & $\mathrm{X} 25$ & & & 0,823 \\
\hline \multirow{3}{*}{6} & \multirow{3}{*}{$\begin{array}{l}\text { Lingkungan tempat } \\
\text { tinggal }\end{array}$} & X62 & \multirow{3}{*}{1,003} & \multirow{3}{*}{$4,558 \%$} & 0,767 \\
\hline & & X63 & & & 0,829 \\
\hline & & X64 & & & 0,766 \\
\hline
\end{tabular}

Sumber: Data primer yang diolah (2019)

Tabel 7 menunjukkan bahwa terdapat satu indikator yang memiliki nilai faktor pembobot kurang dari 0,45 yaitu X44. Tabel 8 menunjukkan bahwa terdapat dua indikator yang memiliki nilai faktor pembobot kurang dari 0,45 yaitu X42 dan X43. Oleh karena itu, interpretasi dilakukan tanpa memasukkan indikator tersebut.

Berdasarkan hasil yang diperoleh dari menganalisis data dengan analisis faktor dapat dilihat bahwa faktor yang memengaruhi anak putus sekolah pada jenjang pendidikan SMP/sederajat di Kabupaten Badung yaitu, kurangnya perhatian orang tua, rendahnya kemauan dan kesadaran anak untuk belajar, ekonomi keluarga, kurangnya kemampuan dan minat anak untuk belajar, buruknya hubungan sosial di sekolah, dan lingkungan tempat tinggal. Faktor yang memengaruhi anak putus sekolah pada jenjang pendidikan SMA/sederajat di Kabupaten Badung yaitu, rendahnya minat dan kemauan anak untuk bersekolah, kurangnya perhatian orang tua, ketidakmampuan mengikuti pelajaran, buruknya hubungan sosial di sekolah, kondisi ekonomi dan mental anak yang tidak stabil, dan lingkungan tempat tinggal. Dari tabel 7 dan tabel 8 dapat dilihat bahwa faktor yang paling dominan dalam memengaruhi anak putus sekolah pada jenjang pendidikan SMP/sederajat adalah kurangnya perhatian orang tua, sedangkan faktor yang paling dominan dalam memengaruhi anak putus sekolah pada jenjang pendidikan SMA/sederajat adalah rendahnya minat dan kemauan anak untuk bersekolah. 
Tabel 8 Hasil Analisis Faktor Data SMA

\begin{tabular}{|c|c|c|c|c|c|}
\hline Faktor & Nama Faktor & Indikator & $\begin{array}{l}\text { Nilai Akar } \\
\text { Ciri }\end{array}$ & $\begin{array}{l}\text { Persentase } \\
\text { Ragam }\end{array}$ & Nilai Pembobot \\
\hline \multirow{5}{*}{1} & \multirow{5}{*}{$\begin{array}{l}\text { Rendahnya minat dan } \\
\text { kemauan anak untuk } \\
\text { bersekolah }\end{array}$} & $\mathrm{X} 11$ & \multirow{5}{*}{4,380} & \multirow{5}{*}{$18249 \%$} & 0,824 \\
\hline & & $\mathrm{X} 12$ & & & 0,788 \\
\hline & & $\mathrm{X} 13$ & & & 0,895 \\
\hline & & $\mathrm{X} 14$ & & & 0,720 \\
\hline & & $\mathrm{X} 15$ & & & 0,653 \\
\hline \multirow{4}{*}{2} & \multirow{4}{*}{$\begin{array}{l}\text { Kurangnya perhatian } \\
\text { orang tua }\end{array}$} & $\mathrm{X} 51$ & \multirow{4}{*}{3,155} & \multirow{4}{*}{$13147 \%$} & 0,788 \\
\hline & & X52 & & & 0,811 \\
\hline & & X53 & & & 0,700 \\
\hline & & $\mathrm{X} 54$ & & & 0,625 \\
\hline \multirow{4}{*}{3} & \multirow{4}{*}{$\begin{array}{l}\text { Ketidakmampuan } \\
\text { mengikuti pelajaran }\end{array}$} & $\mathrm{X} 31$ & \multirow{4}{*}{2,481} & \multirow{4}{*}{$10336 \%$} & 0,736 \\
\hline & & $\mathrm{X} 32$ & & & 0,725 \\
\hline & & $\mathrm{X} 33$ & & & 0,742 \\
\hline & & $\mathrm{X} 34$ & & & 0,654 \\
\hline \multirow{3}{*}{4} & \multirow{3}{*}{$\begin{array}{l}\text { Buruknya hubungan } \\
\text { sosial di sekolah }\end{array}$} & $\mathrm{X} 21$ & \multirow{3}{*}{2,159} & \multirow{3}{*}{$8994 \%$} & 0,776 \\
\hline & & $\mathrm{X} 24$ & & & 0,798 \\
\hline & & $\mathrm{X} 25$ & & & 0,638 \\
\hline \multirow{5}{*}{5} & \multirow{5}{*}{$\begin{array}{l}\text { Kondisi ekonomi dan } \\
\text { mental anak yang tidak } \\
\text { stabil }\end{array}$} & $\mathrm{X} 35$ & \multirow{5}{*}{1,806} & \multirow{5}{*}{$7525 \%$} & 0,456 \\
\hline & & $\mathrm{X} 41$ & & & 0,673 \\
\hline & & $\mathrm{X} 42$ & & & 0,445 \\
\hline & & $\mathrm{X} 43$ & & & 0,412 \\
\hline & & $\mathrm{X} 44$ & & & 0,695 \\
\hline \multirow{3}{*}{6} & \multirow{3}{*}{$\begin{array}{l}\text { Lingkungan tempat } \\
\text { tinggal }\end{array}$} & X62 & \multirow{3}{*}{1,466} & \multirow{3}{*}{$6107 \%$} & 0,590 \\
\hline & & $\mathrm{X} 63$ & & & 0,778 \\
\hline & & X64 & & & 0,829 \\
\hline
\end{tabular}

Sumber: Data primer yang diolah (2019)

\section{KESIMPULAN DAN SARAN}

\section{Kesimpulan}

Berdasarkan hasil dan pembahasan yang diperoleh, dapat disimpulkan beberapa hal seperti:

1. Faktor yang memengaruhi anak putus sekolah pada jenjang pendidikan SMP/sederajat di Kabupaten Badung yaitu, kurangnya perhatian orang tua, rendahnya kemauan dan kesadaran anak untuk belajar, ekonomi keluarga, kurangnya kemampuan dan minat anak untuk belajar, buruknya hubungan sosial di sekolah, dan lingkungan tempat tinggal. Faktor yang memengaruhi anak putus sekolah pada jenjang pendidikan SMA/sederajat di Kabupaten Badung yaitu, rendahnya minat dan kemauan anak untuk bersekolah, kurangnya perhatian orang tua, ketidakmampuan mengikuti pelajaran, buruknya hubungan sosial di sekolah, kondisi ekonomi dan mental anak yang tidak stabil, dan lingkungan tempat tinggal.

2. Terdapat perbedaan antara faktor dominan yang memengaruhi anak putus sekolah pada jenjang pendidikan SMP/sederajat dan SMA/sederajat di Kabupaten Badung. Faktor yang paling dominan dalam memengaruhi anak putus sekolah pada jenjang pendidikan SMP/sederajat adalah kurangnya perhatian orang tua, sedangkan faktor yang paling dominan dalam memengaruhi anak putus sekolah pada jenjang pendidikan 
SMA/sederajat adalah rendahnya minat dan kemauan anak untuk bersekolah.

\section{Saran}

Adapun saran yang dapat disampaikan yaitu, persentase keragaman yang mampu dijelaskan oleh faktor yang terbentuk pada data anak putus sekolah jenjang pendidikan SMA/sederajat hanya sebesar 64,359\%. Hal ini berarti 35,641\% keragaman dijelaskan oleh faktor lain. Pada penelitian selanjutnya diharapkan lebih dipertimbangkan lagi mengenai pemilihan peubah penelitian yang di digunakan agar lebih sesuai dengan kondisi lokasi penelitian, sehingga persentase keragaman yang mampu dijelaskan lebih besar.

\section{DAFTAR PUSTAKA}

BPS Provinsi Bali. (2017). Provinsi Bali dalam Angka 2017. Bali: BPS Provinsi Bali.

Hair JR, J. F., Black, W. C., Babin, B. J., \& Anderson, R. E. (2010). Multivariate Data Analysis. New Jersey: Prentice Hall.

Hill, R. (1998). What Sample is "Enough" in Internet Survey Reasearch? New Zealand: Aect.

Johnson, R. A., dan Winchern, D. W. (2007). Applied Multivariate Statistical Analysis, 6 th edition. New Jersey: Pretice-Hall International, Inc.

Sentana, I Nyoman Budi. (2014). Pelaksanaan Peraturan Daerah Provinsi Bali Nomor 9 Tahun 2009 Terkait dengan Program Wajib Belajar 12 Tahun. Jurnal Magister Hukum Udayana, 5 (3): 447- 463.

Suyanto, B. (2013). Masalah Sosial Anak. Jakarta: Kencana Prenada Media Group. 